DOI: $\underline{\text { https://doi.org/10.24867/12GI02Tomic }}$

\title{
PRIMENA EMBOK MODELA NA PRIMERU ORGANIZACIJE SPORTSKOG DOGAĐAJA
}

\section{APPLICATION OF THE EMBOK MODEL ON THE EXAMPLE OF SPORTS EVENT ORGANIZATION}

\author{
Nataša Tomić, Fakultet tehničkih nauka, Novi Sad
}

\begin{abstract}
Oblast - PROJEKTNI MENADŽMENT
Kratak sadržaj - $U$ radu je analiziran EMBOK model $i$ mogućnost njegove priene u organizovanju sprtskog događaja. Date susugestije, prikazana ograničenja modela iz čega su dobijene i prikazane smernice za prilagođavanje modela ovoj vrsti događaja.
\end{abstract}

Ključne reči: Menadžment, EMBOK Model, Organizacija sportskog događaja.

Abstract - The paper analyzes the EMBOK model and the possibility of its application in organizing a sports event. Suggestions are given, the limitations of the model are shown, from which the guidelines for adapting the model to this type of event are obtained and presented.

Keywords: Management, EMBOK Model, Organization of a sports event.

\section{UVOD}

Predmet istraživanja rada je analiza primene EMBOK modela u organizovanju sportskog događaja.

Cilj rada jeste pružanje smernica za uspešno organizovanje događaja velikog obima. Kompletno sagledavanje istraživanja ima za cilj:

1. da se pojasni pojam i značaj planiranja događaja;

2. da se prikažu tehnike i sredstva za planiranje događaja;

3. da se prikaže značaj stejkholdera prilikom organizovanja događaja;

4. da se objasne svi domeni EMBOK modela;

5. da se prikaže primena EMBOK modela u organizovanju događaja.

Istraživanje je predstavljeno na bazi prethodnih teorijskih saznanja i novootkrivenih empirijskih činjenica. Na osnovu toga, istraživanje se zasniva na sledećim pitanjima:

- Koja su znanja potrebna za planiranje događaja?

- Kako događaj utiče na okruženje (stejkholdere)?

- Da li se EMBOK model može primeniti na organizaciju sportskog događaja?

U cilju boljeg razumevanja tematike ovog rada, opisane su teorijske podloge o organizaciji događaja, pre svega

\section{NAPOMENA:}

Ovaj rad proistekao je iz master rada čiji mentor je bio dr Nenad Simeunović. planiranja, gde je prikazana šira slika i osnovni pojmovi o događajima i profesiji menadžmenta događaja. Zatim je ukazano na važnost stejkholdera i njihovoj pravilnoj identifikaciji $\mathrm{i}$ analizi, ali i o upravljanju i praćenju njihovog angažovanja.

Prikazani su i osnovni modeli koji se koriste $u$ menadžmentu događaja. Druga polovina rada fokusirana je na EMBOK model koji je široko prihvaćen u svetu, mogućnost njegove primene $u$ organizovanju događaja, sa opisom domena od kojih se sastoji i na samom kraju dat je primer primene EMBOK modela na konkretnom događaju.

Organizacija događaja je oblast menadžmenta koja se poslednjih godina razvija neverovatnom brzinom. Osnovna podela događaja jeste na planirane i neplanirane događaje. Planirani događaji su predmet izučavanja menadžmenta događaja i oni zahtevaju detaljno planiranje, izvršioce i određeno vremensko trajanje, dok neplanirane događaje čine različite nezgode, prirodne katastrofe, iznuđene reakcije i slično.

\section{TEORIJSKE PODLOGE O ORGANIZACIJI DOGAĐAJA}

Događaj kao svesna i ekonomski usmerena ljudska aktivnost se pojavila veoma davno. Svaka vrsta događaja sastoji se od mnogobrojnih delova koji se uklapaju i na kraju čine događaj.

Za uspešan događaj potrebno je da se svi ti delovi povežu, odnosno sastave u pravo vreme i napravom mestu, efikasno i po planu. Čitav ovaj proces se naziva menadžment događaja [1].

Događaj predstavlja specifično osmišljenu ponudu ograničenog trajanja, u čijoj osnovi se nalazi odgovarajuća ideja, koja se zajedničkim angažovanjem izvršilaca i materijalnih sredstava ispoljava kao originalna idejna ponuda [2]

Upravljanje događajem uključuje stvaranje, koordinaciju i upravljanje svim različitim komponentama događaja, kao i timove ljudi odgovornih za svaki aspekt.

Strateško planiranje događaja podrazumeva [1]:

1. Koncept davanja ponude

2. Studiju izvodljivosti

3. Pripremu ponude

4. Odluku o nastavku ili prekidu

5. Uspostavljanje organizacione strukture 


\section{Tehnike i sredstva za planiranje događaja}

U fazi planiranja događaja mogu se koristiti razne tehnike i sredstva za prezentaciju informacija klijentima, zaposlenima, publici, sponzorima i sl. Sredstva koja se u tu svrhu koriste su univerzalna sredstva koja se koriste i u raznim drugim prilikama i aktivnostima. Prilikom planiranja događaja najčešće se koriste [3]:

- gantogram,

- rasporedi,

- organizacione šeme,

- mape i makete i

- kontrolne liste.

Detaljnim istraživanjem, pored gore navedenih "osnovnih" alata koji pomažu u planiranju događaja, mogu da se koriste i sledeći softveri[4]:

- Idloom-events

- CVent

- Planstone

- Raklet

- Eventival

- Weemss

- EventGeek

U današnje vreme, kada se susrećemo sa naglim razvojem tehnike i tehnologije, treba napomenuti da je planiranje događaja veoma teško, kako bi se uspešno zadovoljile novonastale želje i potrebe „vlasnika“ događaja. Postoji veliki broj stvari koje se moraju pratiti. Ključ je ostati organizovan. Gore navedeni skup softvera za planiranje i upravljanje događaja u velikoj meri pomaže da se procene mogućnosti i odabere najbolji softver u skladu sa vrstom događaja.

\section{Stejkholderi događaja}

U savremenim uslovima poslovanja, identifikacija stejkholdera je neizostavna. Više nije dovoljno da događaj zadovolji samo potrebe svoje publike. On mora da obuhvati mnoštvo drugih zahteva, uključujući vladine ciljeve i propise, zahteve medija, potrebe sponzora $i$ očekivanja zajednice. Ljudi i organizacije sa legitimnim interesovanjem za rezultate događaja poznati su kao stejkholderi, odnosno zainteresovane strane. Uspešni menadžer događaja mora biti u stanju da prepozna spektar zainteresovanih strana u nekom događaju i upravlja njihovim individualnim potrebama, koje se ponekad mogu i preklapati i sukobljavati. Propusti da se „čuje glas" stejkholdera, kao i da se uzmu u obzir informacije koje poseduju, predstavlja nedostatak u razmišljanju ili akciji organizacije koji dovodi do loših rezultata [1].

Imperativ prilikom upravljanja stejkholderima je razumevanje njihovih potreba i želja, a redovnom komunikacijom se mogu predstaviti njihove potrebe, ali i zahtevi projekta, odnosno događaja. Ukoliko se kreira dobra strategija za upravljanje stejkholderima, neki od benefita se ogledaju u ispunjenju potreba i zahteva stejkholdera, dobija se prijateljski nastrojeno okruženje u kome su stejkholderi voljni da pomognu i da kooperacijom ne naškode događaju. Sve to na kraju dovodi i do manje fluktacije obima događaja, a rizici se mogu mnogo uspešnije izbegavati i prevazilaziti. Dakle, jedan od koraka za uspešno planiranje i izvođenje događaja je i definisanje svih zainteresovanih strana i adekvatno upravljanje istim.

O stejkholderima treba razmišljati već u ranim fazama planiranja projekta ili događaja, kako bi se što pre dobila podrška svih zainteresovanih strana, ukoliko se to ne uradi, projekat i događaj vrlo lako mogu biti osuđeni na propast.

\section{EMBOK model}

Jedan od modela koji je opšteprihvaćen je EMBOK Event Management Body Of Knowledge (korpus znanja menadžmenta događaja). EMBOK model se i dalje razvija i vremenom sve više unapređuje. Može da se primeni na različite kategorije događaja, kao što su: korporacijski događaji, izložbe i sajmovi, festivali, marketinški događaji, humanitarni događaji, sastanci, zabava, sportski događaji i mnogi drugi [5].

Međunarodni EMBOK model je zasnovan na tri dimenzije koje odgovaraju podacima, fazama i procesima upravljanja projektima. Pored toga, osnovne vrednosti važe za sve aspekte upravljanja događajima. Model se sastoji od pet domena znanja. Svaki menadžer događaja mora da upravlja ovim područjima. Drugi hijerarhijski nivo u okviru navedenog modela predstavljaju klase (funkcionalne jedinice ili kategorije) koje obuhvataju niz aktivnosti koje se odnose na organizaciju događaja. [5].

Može se zaključiti da je osnovni cilj međunarodnog EMBOK modela da stvori znanja i procese koji se koriste $\mathrm{u}$ upravljanju događajima i koji mogu da zadovolje različite potrebe zainteresovanih aktera.

\section{Analiza EMBOK modela i mogućnost primene u organizaciji fudbalske utakmice}

EMBOK model je baziran na OLAP sistemu. Aktivnosti ovog informacionog sistema se mogu podeliti u tri grupe: prikupljanje podataka, obrada podataka i korišćenje informacija. Prikupljanje podataka obuhvata sve zahteve za određenim podacima koji se kreću od ad hoc upita do istraživačkih projekata, skeniranja okruženja, pretraživanja ili ponovnog uzimanja informacija iz baze podataka. Obrada podataka se odnosi na evaluaciju informacija, sažimanje i uređivanje podataka i drugih pisanih materijala, opisivanje i kodiranje podataka, što je značajno za pretraživanje informacija, pravovremeno pružanje informacija svim zainteresovanim akterima i izgradnju i održavanje baze podataka (upisivanje novih i brisanje ili modifikovanje postojećih podataka). Korišćenje informacija predstavlja „krunu“ rada informacionog sistema. Menadžerima i drugim korisnicima informacija je potrebna podrška informacionog sistema $\mathrm{u}$ obliku različitih istraživačkih studija, marketinških obaveštenja, periodičnih izveštaja i analiza koje će doprineti poboljšanju sistema odlučivanja [6].

Predmet analize mogućnosti primene EMBOK modela $\mathrm{u}$ organizovanju sportskog događaja je organizacija proslave stogodišnjice fudbalskog kluba "Hajduk" iz Stapara. Događaj je namenjen meštanima sela, kao i ostalim ljudima koji su na bilo koji način imali veze sa klubom. Tema događaja je organizacija utakmice sa fudbalskim 
klubom "Crvena Zvezda" iz Beograda. Na utakmici učestvuju veterani pomenutih klubova, zbog jednostavnije organizacije i atraktivne predstave. Gledaoci su takođe imali priliku da uživo vide velika imena našeg fudbala.

Izabran je adekvatan primer organizovanja događaja i predstavljen je po EMBOK metodologiji. Ceo projekat organizovanja proslave povodom stogodišnjice FK "Hajduk" iz Stapara prolazi kroz pet domena koji se odnose na administraciju, dizajn, marketing, operacije i rizik. U sklopu ovih domena predstavljeni su i klase za svaku aktivnost gde je događaj detaljnije opisan.

\section{Primer primene EMBOK modela na organizovanju stogodišnjice FK “Hajduk" Stapar}

Primena EMBOK modela je opisana na primeru organizovanja fudbalske utakmice. EMBOK model pruža mogućnost da se putem definisanja domena odrede odgovornosti i kompetentnosti tokom projekta.

Dakle, pomenuti model predstavlja okvir koji ilustruje i obuhvata aspekte upravljanja događajima, a pri tome je fleksibilan u skladu sa potrebama korisnika. Zadatak menadžera događaja jeste da nadgleda i organizuje svaki aspect događaja, koji uključuje istraživanje, planiranje, organizovanje, sprovođenje, kontrolu i vrednovanje događaja.

\section{ZAKLJUČAK RADA I PRAVCI DALJIH ISTRAŽIVANJA}

Danas se organizovanje događaja pretvorilo u unosan posao za koji se angažuju eksperti ili agencije koje su za to specijalizovane. Organizatori događaja imaju veliku odgovornost da sve protekne u najboljem redu i onako kako su naručioci posla, odnosno "vlasnici" događaja to zamislili.Planiranje događaja je složen proces, koji mora biti sveobuhvatan i fleksibilan. Ono obuhvata niz značajnih koraka i predstavlja osnovu svakog uspešnog događaja. Menadžer događaja mora jasno da shvati razlog postojanja događaja, odnosno njegovu viziju, misiju, svrhu i ciljeve, ali i da odabere potrebne strategije kojima će se cilj ostvariti. Strategije moraju biti sprovedene kroz čitav niz operativnih planova u skladu sa ukupnim budžetom događaja. Ove planove je potrebno nadgledati i prilagođavati u skladu sa promenama koje se mogu pojaviti.

$\mathrm{Na}$ osnovu sprovedenog istraživanja i detaljne analize EMBOK modela, sa pravom se može reći da on predstavlja veoma dobar okvir po kome je moguće organizovati događaj. Jednostavno, pokazalo se da struktura modela omogućava vrlo značajnu detaljnost i dobar pregled potrebnih aktivnosti koje su neophodne za uspeh projekata.Prednosti ovog modela su što je sveobuhvatni okvir, koji pruža veliki prostor za dalje usavršavanje i izučavanje, daje smernice i ideje, sagledava proces menadžmenta događaja iz različitih uglova i dimenzija, pa se omogućava njegovo bolje razumevanje i obavljanje

Za organizovanje bilo kog događaja, pa i fudbalske utakmice, EMBOK može biti korisno pomoćno sredstvo.
Spisak aktivnosti i odgovornosti koje ovaj model sadrži, služi kao podsetnik i lista stvari koje treba obaviti.

Pored toga, dobro planiranje je presudno za uspeh i konkurentnost organizacije. Ono što značajno može da pomogne jesu alati koji omogućavaju da se postave i prate zadaci, i na taj način omogući njihova realizacija u datim rokovima.

Kao i kod svakog događaja, uvek se javljaju neplanirani problemi, koji se u hodu rešavaju i upravo zbog toga je potrebno na vreme početi sa kompletnom organizacijom. Stoga je bitno shvatiti da iza svakog događaja stoji mnogo rada, truda i odricanja, ali satisfakcija koja se javlja nakon uspešno završenog posla predstavlja najveću nagradu. Svaki događaj je priča za sebe i ima sopstveni koncept, pa prema tome i jedinstvene zahteve koji treba da budu ispunjeni.

Na samom kraju događaja ostaje iskustvo. Ono može da posluži za budućnost i kroz detaljne izveštaje može ukazati na eventualne propuste koji će se, ukoliko se opet pojave, rešiti sa lakoćom.

\section{LITERATURA}

[1] Glenn A. J. Bowdin, Johnny Allen, William O'Toole, Robert Harris and Ian McDonnell (2006). Event management Second edition, Elsevier Ltd.

[2] Getz, D. (1991). Festivals, Special Events and Tourism. New York, Van Nostrand Reinhold.

[3] Ketaki S. Pathak (2015). The Advantages of Using Project Management tools in Industries, Ashoka Center for Business and Computer studies, Nashik, India.

[4] Capterra - Event Management Software. [Online] [Cited: July 27, 2020.] https://www.capterra.com/eventmanagement-

software/?fbclid=IwAR2fopnp6XIwzQS9ItXtmdAlhCYr Ok6VEOPaJzRDB909itAVReYCimI2VNM

[5] Silvers, J. R., Bowdin, G. A. J., O’Toole, W. J., \& Nelson, K. B. (2005). Towards an International Event Management Body of Knowledge (EMBOK). Event

[6] International EMBOK - Event Management Body Of Knowledge [Online] [Cited: jul 23, 2020.] https://www.embok.org/

\section{Kratka biografija:}

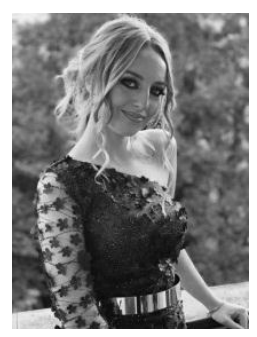

Nataša Tomić, rođena je u Somboru 1996. godine. Master rad na Fakultetu tehničkih naukaiz oblasti Projektnog menadžmenta - Menadžment događaja odbranila je 2020. godine. Kontakt: tomicka.n.996@gmail.com 